Cassia Ayumi Takahashi

\title{
ASSIMILAÇÃO DO NITROGÊNIO EM DIFERENTES REGIÕES FOLIARES DE UMA BROMÉLIA EPÍFITA COM TANQUE
}

São Paulo

2008 


\section{RESUMO}

A folha é o principal órgão de absorção e assimilação de nutrientes dos membros epífitos com tanque da família Bromeliaceae. Pouco se conhece sobre a nutrição dessas bromélias, entretanto algumas evidências (TAKAHASHI, 2007) indicaram a possibilidade de haver uma absorção preferencial do nitrogênio na porção basal e a assimilação desse nutriente na porção apical foliar.

Para se compreender melhor os mecanismos de assimilação do nitrogênio utilizados pelas bromélias epífitas com tanque, foi proposto neste trabalho dois principais objetivos: 1) verificar possíveis diferenças quanto à capacidade de assimilação do nitrogênio em diferentes porções foliares de uma bromélia epífita com tanque; 2) constatar possível preferência em assimilar fonte nitrogenada orgânica ou inorgânica, quando ambas estão disponíveis no interior do tanque.

A estratégia utilizada para o primeiro objetivo foi cultivar bromélias da espécie Vriesea gigantea, cultivadas em casa de vegetação e registrar em suas folhas as variações temporais das atividades enzimáticas da urease, redutase do nitrato (NR), sintetase da glutamina (GS), desidrogenase do glutamato dependente de NADH (GDH-NADH) e arginase após o fornecimento, no interior do tanque das bromélias, de uma solução nutritiva contendo $\mathrm{NO}_{3}{ }^{-} / \mathrm{NH}_{4}{ }^{+}$(3:2) ou uréia (5mM de $\mathrm{N}$ total), como fontes de nitrogênio. Foram analisadas as atividades enzimáticas nas porções apical e basal foliar de Vriesea gigantea nos seguintes tempos: 0, 1, 3, 6, 9, 12, 24, 48, 51, 54, 57, 60 e 73 horas após a rega. Além disso, também foram quantificadas as concentrações do amônio e da uréia endógenos presentes nos tecidos foliares de ambas as porções. Os resultados mostraram que, independente do tratamento, as atividades de GS, GDH e arginase foram mais altas na porção apical em todos os tempos de coleta. Já as atividades da NR e urease, foram crescentes e mais intensas na porção basal, da mesma forma como foi visto para as concentrações endógenas de amônio durante as primeiras 24 horas. As maiores concentrações de uréia endógenas também foram registradas principalmente na porção basal foliar. Esses resultados permitem inferir que a região apical pode estar envolvida, preferencialmente, com a assimilação do nitrogênio, enquanto que a basal, com a sua absorção, redução do nitrato e hidrólise da uréia. Além disso, sugere-se também que ocorra o transporte de amônio da base para a região de sua assimilação em aminoácidos (ápice) através do xilema e apoplasto. 
Em relação ao segundo objetivo, a estratégia utilizada foi fornecer à bromélia Vriesea gigantea com uma solução nutritiva que continha 5mM de nitrogênio total, disponível na forma inorgânica + orgânica $\left(\mathrm{NH}_{4}{ }^{+} / \mathrm{NO}_{3}{ }^{-}+\right.$uréia nas proporções $1: 1$ ou $1: 3$, respectivamente). Como controle foram empregados os seguintes tratamentos: ausência de nitrogênio e presença de somente fontes inorgânicas (5mM de nitrogênio total). As porções apical e basal das folhas foram coletadas 9 horas após o fornecimento das soluções nutritivas e, posteriormente, utilizadas nas análises enzimáticas referentes às atividades da urease, NR, GS, e GDH-NADH. Além disso, foram quantificados em ambas as porções os teores endógenos de amônio, uréia, amido, açúcares totais e clorofila total. Também foram determinados as densidades de tricomas e estômatos nas duas regiões foliares. Verificou-se que as maiores atividades da GS (porção apical) e GDH (porção basal) foram registradas nos dois tratamentos com uréia (1:1 e 1:3) quando comparadas com as dos dois controles. As maiores concentrações de amônio endógeno na porção basal também foram detectadas nos mesmos tratamentos com uréia (1:1 e 1:3). Já a atividade da NR apresentou os maiores valores nos tratamentos de proporção 1:1 e no controle 2 (com somente fontes inorgânicas) na porção basal foliar. De modo interessante, a GS não mostrou o mesmo desempenho nos dois tratamentos (1:1 e controle 2), sendo que, no tratamento de proporção 1:1, a atividade foi o dobro daquela registrada no controle 2. Todos esses resultados analisados em conjunto permitem inferir que a bromélia Vriesea gigantea pode ter preferência por assimilar o nitrogênio proveniente da uréia quando essa fonte se encontra disponível no interior do tanque, mesmo quando também há a presença de formas inorgânicas (nitrato e amônio). 
The leaf is considered the most important vegetative organ of tank epiphytic bromeliads due to its ability to absorb and assimilate nutrients. Little is known about the nutrition of these bromeliads, but there are evidences that the basal region of the leaf may be preferentially involved with the absorption of nutrients, whereas the apical region may be involved with its assimilation (TAKAHASHI, 2007).

In order to better understand the mechanisms utilized by these tank epiphytic bromeliads to optimize the nitrogen acquisition and assimilation, it was proposed in this study two main objectives: 1) verify the existence of a differential capacity to assimilate nitrogen in different leaf portions of a tank epiphytic bromeliad; 2) analyze the nitrogen assimilation preference between inorganic and organic nitrogen sources when both are available in the tank water.

The experiments of the first objective were conducted using Vriesea gigantea plants, a typical specie of tank epiphytic bromeliad, cultivated in greenhouse. Nutrient solution containing $\mathrm{NO}_{3}{ }^{-} / \mathrm{NH}_{4}{ }^{+}$(3:2) or urea as nitrogen source ( $5 \mathrm{mM}$ of total $\mathrm{N}$ ) was supplied into the tank of these plants and the activities of urease, nitrate reductase (NR), glutamine synthetase (GS), NADH-dependent glutamate dehydrogenase (GDH$\mathrm{NADH}$ ) and arginase were quantified in apical and basal leaf portions after $0,1,3,6,9,12,24,48,51,54$, 57, 60 and 73 hours. The ammonium and urea present in the tissues were also analyzed. Independent of the nitrogen source utilized, GS, GDH and arginase activities were higher in the apical portions of leaves in all the period analyzed. On the other hand, the opposite was observed in relation to NR and urease activities. The highest activities were detected in the basal portion of leaves at all harvest times, with increasing values during the first 24 hours of experiment. Interestingly, this same pattern was also observed in relation to the endogenous ammonium and urea: the highest contents were detected in the basal portion of leaves, with a gradual increase of ammonium in the first 24 hours of analysis. These results suggest that the basal portion of leaves was preferentially involved in nitrogen uptake, nitrate reduction and urea hydrolysis, while the apical portion was the main responsible for nitrogen assimilation. Moreover, it was possible to infer that the ammonium may be transported from the base (uptake region) to the apex of the leaves (the main nitrogen assimilation region) through the xylem and apoplast. 
In order to analyze the nitrogen assimilation preference of Vriesea gigantea, a nutrient solution containing $5 \mathrm{mM}$ of nitrogen containing a mixture of inorganic and organic sources $\left(\mathrm{NH}_{4}^{+} / \mathrm{NO}_{3}{ }^{-}+\right.$urea in the proportion $1: 1$ or $1: 3$, respectively) were supplied into the tank of the bromeliads. As a control, a nutrient solution containing no nitrogen source (control 1) or $5 \mathrm{mM}$ of inorganic nitrogen sources (control 2) were used. The basal and apical leaf tissues were collected after 9 hours and the activities of urease, NR, GS and GDH-NADH were analyzed. Endogenous ammonium, urea, starch, total soluble carbohydrates and total chlorophyll were also quantified. Furthermore, the density of trichomes and stomata were also analyzed on the abaxial leaf surface of both regions. The highest activities of GS (apex) and GDH (base), as well as the endogenous ammonium content (base), were registered in both treatments with urea (1:1 and 1:3) in comparison with both controls. A different pattern was obtained analyzing NR: the highest activities were observed in plants that received nutrient solutions containing only inorganic nitrogen (control 2) or a mixture of inorganic and organic nitrogen in the proportion 1:1. Moreover, an interesting behavior was observed in relation to the GS activity: it was detected the double activity of this enzyme when Vriesea gigantea was in contact with a mixture of inorganic and organic nitrogen (1:1) in comparison to the plants in the presence of only inorganic nitrogen sources. All results suggest that Vriesea gigantea may have preference to assimilate organic nitrogen source (urea), when the inorganic nitrogen sources (ammonium and nitrate) are also available in the tank water. 


\section{INTRODUÇÃO}

I.1- Nutrição de bromélias epífitas com tanque

A família Bromeliaceae distribui-se ao longo de toda zona tropical e subtropical das Américas, sendo a América do Sul considerada como o centro de grande diversidade (LEME, 1993). O sucesso dessa ampla distribuição geográfica pode ser explicado pelo desenvolvimento de especializações morfológicas e fisiológicas que permitiram a sobrevivência e a adaptação dessas espécies a diferentes condições ambientais (PADILHA, 1973). A diferença na disponibilidade de nutrientes em cada ecossistema é um fator ambiental que pode estar relacionado à existência das características adaptativas que melhoram a eficiência da aquisição de nutrientes das bromélias de acordo com seu hábito de vida (BENZING \& RENFROW, 1974).

As bromélias de hábito terrestre absorvem os nutrientes do solo através das raízes bem desenvolvidas (BENZING \& RENFROW, 1974). Diferentemente dessas, as bromélias de hábito epífito apresentam um sistema radicular bastante reduzido, cuja principal função é a sua fixação na planta hospedeira. Dessa forma, a função de absorção de água e nutrientes passou a ser executada quase totalmente por um outro órgão: as folhas cobertas por tricomas absorventes (BENZING, 1990). Muitas bromélias epífitas possuem suas folhas dispostas em torno do seu eixo caulinar com uma sobreposição parcial entre elas, formando o que se denominou de tanque ou cisterna (LEME, 1993).

O tanque é uma estrutura importante na obtenção de nutrientes pelas bromélias epífitas, pois a disposição das folhas permitiu com que os nutrientes, como minerais, íons e até mesmo aminoácidos pudessem ser acumulados e posteriormente ser absorvidos pelos tricomas foliares (BENZING, 1990). Muitos trabalhos tentam compreender como ocorre a assimilação desses nutrientes pelos tricomas por meio de estudos anatômicos (KRAUSS, 1949; BENZING \& BURT, 1970; BENZING et al., 1976; SAKAI \& SANDFORD, 1980; BENZING, 1990). A anatomia pode ser uma ótima ferramenta para aprofundar os conhecimentos da fisiologia da nutrição das bromélias (MAXIMOV, 1930).

Os fatores atmosféricos como o vento, a neblina e a chuva transportam minerais sólidos até as cisternas, contribuindo para a riqueza nutricional do tanque (LEME, 1993). A planta hospedeira também tem um importante papel no fornecimento de nutrientes para as bromélias, além de ser um substrato para sua fixação. Durante os momentos de chuva, os íons e aminoácidos presentes nos troncos e folhas da planta 
hospedeira são levados pela água da chuva até o interior das cisternas, onde são acumulados (BENZING, 1973). Os detritos vegetais depositados no tanque, como material foliar e camadas superficiais de troncos e galhos do hospedeiro, formam um tipo de solo orgânico (húmus) que também tem grande valor nutricional para as bromélias (BENZING, 1973; LEME, 1993).

Há outras formas de obtenção de nutrientes pelas bromélias epífitas. Segundo Benzing (1990), formigas que vivem em associação com algumas bromélias depositam outros insetos, capturados por elas, no interior das cavidades das cisternas. Esses detritos animais e as próprias excretas das formigas enriquecem o tanque de nutrientes. As epífitas com tanque também têm associações com uma extensa microflora, diversos invertebrados e alguns vertebrados que geralmente procuram essas plantas como um local de proteção, alimentação e/ou reprodução (BENZING, 2000). Essas associações possibilitam um aumento na disponibilidade de nutrientes nitrogenados inorgânicos como amônio, secretado por cianobactérias (RAI et al, 1983), ou orgânicos, como a uréia, excretada pelos anfíbios viventes em bromélias com tanque (BENZING, 1990).

\section{I.2- A folha como órgão de absorção e assimilação}

A folha é o principal órgão do corpo vegetativo dos membros da família Bromeliaceae (BENZING, 2000). Nas bromélias epífitas com tanque, elas possuem tanto a função de absorção quanto de assimilação dos nutrientes (BENZING, 2000). A folha de uma bromélia tanque pode ser dividida em pelo menos três regiões principais: a porção da base da folha, a qual forma o tanque e, portanto, geralmente está em contato com a água e nutrientes (BENZING, 1990) e as porções mediana e do ápice que estão mais expostas à luz do que a base (POPP et al., 2003).

São raros os trabalhos que mostram a existência de diferenças morfológicas, anatômicas ou fisiológicas entre diferentes regiões de uma mesma folha em bromélias. Sakai \& Sandford (1980), ao estudarem os tricomas presentes nas superfícies foliares de Ananas comosus (Bromeliaceae), observaram que os tricomas presentes no ápice apresentavam-se não funcionais, diferentemente dos tricomas da base.

Popp et al. (2003) verificaram que existem grandes diferenças entre as porções da base e do ápice foliar quando quantificaram alguns tipos de açúcares nos tecidos foliares de Ananas comosus cv. Spanish Red. Em geral, a porção do ápice foliar apresentou maior acumulação de açúcares nos tecidos do que a porção basal. Além disso, esses autores também estudaram a translocação desses carboidratos durante o 
período noturno em direção as partes jovens da planta, gemas e meristemas. Observou-se que a contribuição que cada parte da folha oferece às porções mais novas da planta (dreno) não foi semelhante, sendo que a taxa de dreno desses carboidratos foi maior na porção basal foliar do que na apical (POPP et al., 2003).

Apesar desses poucos trabalhos mostrarem algumas diferenças anatômicas e fisiológicas entre as porções do ápice e da base foliar, nenhum deles propôs alguma hipótese sobre essas porções exercerem diferentes funções nas bromélias.

\section{I.3- Uréia como fonte de nitrogênio}

O nitrogênio é um elemento mineral que as plantas necessitam em grande quantidade. Ele é importante para o crescimento e desenvolvimento das plantas, pois é um constituinte essencial de muitos componentes celulares, incluindo aminoácidos e ácidos nucléicos. As fontes de nitrogênio estão disponíveis para as plantas preferencialmente na forma de nitrato, amônio ou nitrogênio atmosférico, sendo que essa última forma é restrita às plantas que estabelecem associações simbióticas com bactérias fixadoras de nitrogênio (CORDEIRO, 2004).

Como descrito anteriormente, fontes de nitrogênio orgânico podem também ser utilizadas por alguns grupos de plantas pertencentes à família Bromeliaceae (MERCIER et al., 1997). As bromélias epífitas formadoras de tanque parecem possuir adaptações fisiológicas que as capacitam a utilizar com grande eficiência a uréia como fonte nitrogenada (ENDRES \& MERCIER, 2001a; 2001b). NIEVOLA et al. (1997; 2001b) mostraram que a espécie rupícula com tanque, Vriesea fosteriana, está mais adaptada a assimilar o nitrogênio de origem orgânica (uréia) do que a espécie terrestre sem tanque Pitcairnia flammea.

\section{I.4- Metabolismo do nitrogênio}

\section{I.4.1- Redutase do nitrato e urease}

$\mathrm{O}$ nitrogênio presente no $\mathrm{NO}_{3}{ }^{-}$e na uréia pode ser assimilado em aminoácidos pelas plantas, apenas quando esses compostos nitrogenados são reduzidos ou hidrolizados, respectivamente, formando $\mathrm{NH}_{4}{ }^{+}$. A redução completa do $\mathrm{NO}_{3}{ }^{-}$até $\mathrm{NH}_{4}{ }^{+}$ocorre principalmente nas folhas e raízes e é um processo que requer 8 elétrons (SODEK, 2004). Na célula, a redução ocorre em duas etapas, cada uma envolvendo doadores de elétrons específicos. No primeiro passo, após ser absorvido, o $\mathrm{NO}_{3}{ }^{-}$é reduzido a $\mathrm{NO}_{2}{ }^{-}$pela enzima redutase do nitrato (NR) localizada no citossol (TAIZ \& ZEIGER, 2000). A NR pode ser considerada uma enzima 
monoespecífica ou biespecífica, pois dependendo da espécie vegetal, ela pode ter o NADH e/ou NADPH como seus doadores de elétrons (SODEK, 2004).

$\mathrm{O} \mathrm{NO}_{2}{ }^{-}$produzido pela redução do $\mathrm{NO}_{3}{ }^{-}$é citotóxico, devendo ser rapidamente reduzido a $\mathrm{NH}_{4}{ }^{+}$. A enzima responsável por essa segunda etapa é denominada de redutase do nitrito (NiR) que utiliza a ferredoxina como co-fator e está localizada no cloroplasto (tecidos clorofilados) ou plastídeos (tecidos não clorofilados) (HELDT, 1997). As reações catalisadas pela NR/NiR estão descritas a seguir:

$$
\begin{array}{cc}
\mathrm{NO}_{3}^{-}+\mathrm{NAD}(\mathrm{P}) \mathrm{H}+\mathrm{H}^{+}+2 \mathrm{e}^{-} \longrightarrow \mathrm{NR}_{2}^{-}+\mathrm{NAD}(\mathrm{P})^{+}+\mathrm{H}_{2} \mathrm{O} \\
\mathrm{NO}_{2}^{-}+6 \mathrm{Fd}_{\mathrm{red}}+8 \mathrm{H}^{+}+6 \mathrm{e}^{-} \longrightarrow \mathrm{NiR} & \mathrm{NH}_{4}^{+}+6 \mathrm{Fd}_{\mathrm{oxi}}+2 \mathrm{H}_{2} \mathrm{O}
\end{array}
$$

Por outro lado, muitas plantas conseguem absorver a uréia rapidamente pelas folhas (WITTWER et al., 1963; NICOULAUD and BLOOM, 1996). Após ser absorvida, a uréia pode ser hidrolisada no citossol pela enzima urease, gerando dióxido de carbono e amônio (LEHNINGER, 2000). A atividade da urease já foi detectada em muitas plantas (HOGAN et al., 1983; WITTE \& MEDINA-ESCOBAR, 2001) e em alguns trabalhos com arroz (MATSUMOTO et al., 1966), feijão (MATSUMOTO et al., 1968) e cevada (CHEN \& CHING, 1988), foi demonstrado sua preferência pela uréia. A urease é uma metaloenzima contendo o níquel como grupo prostético e parece ser essencial para tornar o nitrogênio da uréia acessível às plantas (GERENDÁS et al., 1999). A seguir é descrito a reação catalisada pela urease:

$$
\text { uréia } \stackrel{\text { urease }}{\longrightarrow} 2 \mathrm{NH}_{4}^{+}+\mathrm{CO}_{2}
$$

I.4.2- Sintetase da glutamina e sintase do glutamato

$\mathrm{O} \mathrm{NH}_{4}{ }^{+}$pode ser incorporado em aminoácidos pela ação combinada da sintetase da glutamina (GS) e sintase do glutamato (GOGAT). A GS é uma importante enzima do metabolismo do nitrogênio. Ela tem grande afinidade pela molécula de amônio e está presente em todos os tecidos vegetais (MIFLIN \& HABASH, 2002). Conhecem-se duas isoformas de GS nas plantas: uma presente no citossol (GS-1) e outra localizada nos cloroplastos ou nos plastídios (GS-2) das raízes. Ambas as formas têm a função de combinar o 
amônio com o glutamato para produzir glutamina. Essa reação necessita da hidrólise de um ATP e envolve um cátion divalente, como o $\mathrm{Mg}^{+2}, \mathrm{Mn}^{+2}$ ou $\mathrm{Co}^{+2}$ como co-fator (SODEK, 2004).

Posteriormente, a glutamina formada tem o seu grupo amida transferido para o 2-oxoglutarato, produzindo duas moléculas de glutamato (LEA, 1993). A enzima responsável por essa reação é a glutamato sintase (GOGAT) que pode estar presente nas plantas em duas formas: uma cloroplastídica, dependente de ferredoxina e outra plastídica, dependente de NADH e encontrada nos tecidos não fotossintetizantes (TAIZ \& ZEIGER, 2000). As reações catalisadas pela GS/GOGAT estão descritas a seguir, resumidamente.

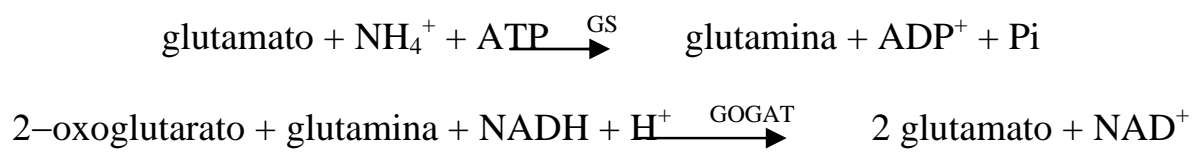

ou

2-oxoglutarato + glutamina $+\mathrm{Fd}_{\mathrm{red} \longrightarrow \text { GOGAT }}^{\longrightarrow} 2$ glutamato $+\mathrm{Fe}_{\text {oxi }}$

As enzimas GS-2 e Fd-GOGAT trabalham em conjunto no cloroplasto. Elas são as duas isoformas mais importantes nos tecidos verdes das plantas, pois apesar da atividade da GS ser também encontrada fora do cloroplasto (GS-1), ela é relativamente baixa comparativamente à enzima do cloroplasto (GS-2) (SODEK, 2004). O sistema GS-2/Fd-GOGAT é importante, pois além de realizar a re-fixação do amônio liberado pela fotorespiração, a Fd-GOGAT, pode contribuir substancialmente para a síntese de glutamato durante a assimilação primária do nitrogênio com a finalidade de suprir a demanda desse aminoácido na planta inteira (BECKER et al.,2000).

A compreensão da regulação da GS e GOGAT é bastante complexa. Dependendo do tecido, da célula ou do compartimento celular em que essas enzimas se localizam ou do estágio de desenvolvimento do órgão vegetal, as atividades dessas enzimas são diferentes. Fatores como as condições ambientais e o ciclo diurno também influenciam as suas atividades (MIFLIN \& HABASH, 2002). Segundo STÖHR \& MÄCK (2001), a atividade da GS citossólica nas raízes de tabaco variou no decorrer das 24 horas. Ela mostrou-se crescente nas primeiras horas do período luminoso. Diferentemente, a GS plastídica foi muito pouco afetada pelas mudanças de claro e escuro. Acredita-se que haja múltiplos controles de regulação atuando em nível gênico e/ou protéico que modificariam a atividade da GS (MIFLIN \& HABASH, 2002). 
É importante considerar essa complexidade ao se estudar a GS e a GOGAT, pois as suas funções em conjunto com as de outras enzimas permitem à planta balancear o metabolismo do carbono e nitrogênio em diferentes órgãos e regiões celulares, nas diferentes horas do dia e sob diversas condições ambientais (MIFLIN \& HABASH, 2002). Segundo Lawlor (2002), compreender os processos bioquímicos, moleculares e fisiológicos das plantas de valor econômico é a melhor forma para se conseguir elaborar novas estratégias que permitam aumentar a produtividade de alimentos sem a necessidade do uso excessivo de fertilizantes.

\section{I.4.3- Desidrogenase do glutamato}

A desidrogenase do glutamato (GDH) é outra enzima que parece ter uma importante função no metabolismo do nitrogênio (MIFLIN \& HABASH, 2002). Antes da descoberta da via de assimilação GS/GOGAT, acreditava-se que a GDH tinha a função única de catalisar a síntese de glutamato a partir de $\mathrm{NH}_{4}{ }^{+}$e 2-oxoglutarato. Entretanto, o trabalho de CAMMAERTS \& JACOBS (1985) sugeriu um duplo papel para essa enzima. Na presença de altas concentrações de $\mathrm{NH}_{4}{ }^{+}$, a GDH atuaria no sentido de assimilação do amônio, enquanto que a GDH-desaminante, forneceria esqueletos carbônicos quando existissem concentrações mais baixas do íon amoniacal. Assim, a GDH faria uma ligação entre os metabolismos de carbono e de nitrogênio.

Conhecem-se duas formas de GDH: uma mitocondrial, dependente de NADH, e outra cloroplastídica, dependente de NADPH (SODEK, 2004). A reação reversível catalisada por essa enzima está esquematizada a seguir:

$$
\text { 2-oxoglutarato }+\mathrm{NH}_{4}^{+}+\mathrm{NADH} \longrightarrow \text { GDH } \quad \text { glutamato }+\mathrm{H}_{2} \mathrm{O}+\mathrm{NAD}^{+}
$$

Atualmente, considera-se a hipótese de que a principal função dessa enzima esteja relacionada com o catabolismo do glutamato, formando 2-oxoglutarato, o qual poderá ser utilizado no ciclo de Krebs (LEA, 1993). Stitt et al. (2002) sugerem que a GDH possa ter um papel cuja ação da enzima varia de acordo com as necessidades celulares com relação aos conteúdos de glutamato e esqueletos carbônicos. Entretanto, há muitos pesquisadores que argumentam que o papel da GDH ainda não está totalmente esclarecido (OAK, 1995). 
Segundo a literatura, a GDH presente nas folhas responde a diversos estímulos ambientais incluindo estresse hídrico, estresse de temperatura, estado nutricional, metais tóxicos ou herbicidas (OSUJI et al., 1998). A atividade da GDH e a expressão do seu gene são diferentemente reguladas de acordo com a disponibilidade de esqueletos carbônicos e compostos nitrogenados no interior da célula (CAMMAERTS \& JACOBS, 1985). Além disso, a GDH pode ser influenciada pelos fitormônios (OSUJI et al., 1998) e é estimulada durante a senescência (MASCLAUX et al. 2001). Entretanto, o papel da GDH nas folhas com relação à reassimilação do amônio liberado durante a quebra de proteínas ou na geração de esqueletos carbônicos via desaminação oxidativa do glutamato ainda é bastante controverso (BECKER et al.,2000)

\section{I.4.4- Arginase}

A arginase é uma enzima que ocorre amplamente na natureza. Ela é responsável por realizar a hidrólise da arginina, produzindo ornitina e uréia (LEHNINGER, 2000). A reação da arginase está descrita a seguir:

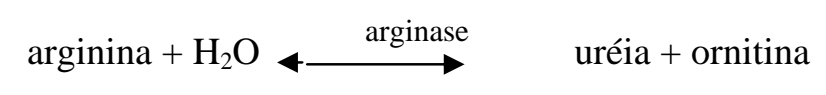

Essa enzima tem sido estudada extensivamente nos tecidos animais, particularmente em relação à excreção de nitrogênio e ao ciclo da uréia (Krebs-Henseleit) (POREMBSKA, 1973). É uma proteína ligeiramente ácida ( $\mathrm{pI} \approx 5.6$ ), altamente específica por arginina, tendo localização mitocondrial (KOLLÖFFEL \& DIJKE, 1975; TAYLOR \& STEWART, 1981) e sua atividade depende da presença de $\mathrm{Mn}_{2}{ }^{+}$como cofator (BOUTIN, 1982).

Diferentemente da arginase de animais e microorganismos, a arginase vegetal é pouco conhecida e estuda. Essa enzima tem sido associada, principalmente, com a hidrólise das reservas nitrogenadas em órgãos de reserva de muitas espécies vegetais (POLACCO \& HOLLAND, 1993; NORDIM \& NAESHOLM, 1997). Tem grande importância no brotamento (de tubérculos e bulbos) e/ou na germinação de sementes (SPLITTSTOESSES, 1969; KOLLÖFFLE \& VAN DIJKE, 1975; KANG \& CHO, 1990; POLACCO \& HOLLAND, 1993; ZONIA et al., 1995; KING \& GIFFORD, 1997; NORDIM \& NAESHOLM, 1997), fornecendo, tanto compostos que atuariam como fontes de nitrogênio quanto esqueletos carbônicos para os eixos em crescimento. Além disso, um dos seus produtos, a ornitina, é precursor da prolina e/ou poliaminas e 
o nitrogênio contido na uréia, o outro produto da arginase, é reciclado pela atuação da urease, a qual libera amônio (POLACCO \& HOLLAND, 1993).

Embora na literatura, a arginase seja considerada uma enzima somente capaz de hidrolisar a arginina em uréia e ornitina (LEHNINGER, 2000), há um único relato sobre a possibilidade da uréia ser incorporada diretamente na formação de arginina (REINBOTHE \& MOTHES, 1962).

Nesses últimos anos, uma nova linha de estudo está sendo desenvolvida no Laboratório de Fisiologia Vegetal do IBUSP, a fim de se investigar a existência de uma rota alternativa de assimilação de uréia através da enzima arginase (CAMBUÍ, resultados não publicados). Embora não há trabalhos que demonstrem claramente sobre a possibilidade da arginase assimilar diretamente a uréia em aminoácidos, um resultado intrigante foi verificado em um experimento onde se cultivou in vitro a bromélia da espécie Vriesea gigantea em um meio contendo uréia como única fonte nitrogenada. Observou-se que após 24 horas de cultivo, as folhas apresentaram uma intensa atividade da arginase, enquanto que detectaram-se níveis muito baixos de atividade da urease (CAMBUÍ, resultados não publicados). Esse estudo também mostrou diferenças muito marcantes no conteúdo endógeno de amônio de plantas que foram cultivadas in vitro na presença de uréia, sugerindo que grande parte desse composto orgânico não estaria sendo hidrolisado; além disso, a uréia não mostrou ser acumulada nos tecidos, embora tenha sido absorvida rapidamente do meio externo (CAMBUÍ, resultados não publicados).

Com o objetivo de se encontrar outras evidências que possam fortalecer a hipótese da existência de uma via alternativa de assimilação de uréia pela ação da arginase e de verificar se esses resultados também eram possíveis de serem detectados em bromélias adultas cultivadas em casa de vegetação, decidiu-se fazer um teste experimental dentro das condições descritas no estudo do tópico IV.1.1. Dosou-se as atividades enzimáticas da arginase nas duas porções foliares de exemplares adultos de Vriesea gigantea, que foram regadas com uma solução nutritiva contendo uréia, como única fonte de nitrogênio, no interior do tanque dessas bromélias (vide tópico IV.1.1). 
I.5- Porções apical e basal das folhas de bromélias epífitas com tanque desempenhariam diferentes funções no metabolismo do nitrogênio?

A hipótese do trabalho foi verificar se a base foliar poderia desempenhar, principalmente, a função de absorção de nitrogênio (região do tanque), enquanto que o ápice seria responsável preferencialmente por sua assimilação. Para isso, estudou-se a assimilação do nitrogênio proveniente de fontes inorgânicas $\left(\mathrm{NH}_{4}{ }^{+} / \mathrm{NO}_{3}{ }^{-}\right)$ou orgânica (uréia) por meio das atividades enzimáticas de quatro enzimas importantes do metabolismo do nitrogênio - urease, NR, GS e GDH-NADH - nas duas porções foliares.

Há outros parâmetros que foram analisados para complementar o estudo das atividades enzimáticas. As quantificações de uréia e amônio endógenos possibilitaram verificar em qual porção foliar estava ocorrendo, preferencialmente, a acumulação de uréia absorvida e do amônio produzido. A determinação da densidade de tricomas foi outro importante fator a ser considerado, pois os tricomas são as principais estruturas de absorção dos nutrientes presentes no tanque (BENZING, 2000).

A porção do ápice das folhas poderia ser a região em que a atividade fotossintética seja mais intensa, uma vez que é a região que fica mais exposta à luz, quando comparada à porção basal. Se considerarmos essa hipótese, para uma região onde a taxa fotossintética é mais elevada, seria pertinente esperar que as atividades das enzimas do metabolismo do nitrogênio também fossem mais intensas. Uma atividade elevada da GS permitiria uma maior síntese de aminoácidos e, conseqüentemente, de proteínas necessárias à manutenção do funcionamento dos processos metabólicos da planta, como a fotossíntese, além de manter o crescimento e desenvolvimento do vegetal (FUENTES et al., 2001). Dessa forma, determinar a densidade de estômatos foi um parâmetro interessante, pois o estômato é a estrutura responsável pela regulação das trocas gasosas, influenciando diretamente a fotossíntese e a produtividade (PIMENTA, 2004). O teor de clorofila total também foi uma medida efetuada nesse trabalho, porque esse pigmento está diretamente relacionado com a atividade fotossintética (MAJEROWICZ, 2004). Além disso, foram quantificados os teores de açúcares solúveis totais e amido, pois os carboidratos são os principais produtos da fotossíntese (MAJEROWICS, 2004). 


\section{II - RESUMO DOS PRINCIPAIS RESULTADOS E CONCLUSÕES}

Nesse trabalho, foi mostrado que as folhas da bromélia Vriesea gigantea foram capazes de absorver e assimilar rapidamente o nitrogênio, tanto inorgânico quanto o orgânico, assim que ele foi disponibilizado no interior do tanque. Nas primeiras 24 horas, já era possível verificar um aumento significativo das atividades da NR e da urease na porção basal foliar, além de um aumento gradual da concentração de amônio e uréia endógena na mesma região. O registro do aumento gradual das atividades da GS e GDH, principalmente na porção apical foliar, entre a $1^{\mathrm{a}}$ e a $24^{\mathrm{a}}$ hora mostrou que as enzimas responsáveis pela assimilação do nitrogênio nos primeiros aminoácidos acompanharam a dinâmica temporal do metabolismo do nitrogênio desencadeado, inicialmente, pela redução do nitrato ou pela hidrólise da uréia por meio das enzimas NR e urease, respectivamente.

Os aumentos das atividades da NR e urease verificados apenas na porção basal e as maiores atividades de GS e GDH detectadas, principalmente, na porção apical das folhas de Vriesea gigantea em resposta ao fornecimento de $\mathrm{NO}_{3}{ }^{-} / \mathrm{NH}_{4}{ }^{+}$(3:2) ou uréia sugerem que a região apical pode estar envolvida, preferencialmente, com a assimilação do nitrogênio amoniacal, enquanto que a basal com a absorção de compostos nitrogenados, redução do nitrato e hidrólise da uréia. Essa hipótese de divisão de funções em diferentes partes da folha de uma bromélia torna-se mais plausível quando se considera ainda a correlação inversa obtida para as densidades de tricomas (estruturas foliares especializadas na absorção de água e nutrientes) e estômatos entre essas duas porções foliares, existindo um gradiente de aumento de tricomas e diminuição de estômatos do ápice para a base.

A porção apical das folhas de Vriesea gigantea também pode ser considerada a região que apresenta uma maior taxa de fotossíntese líquida quando comprada com a base, já que o ápice foi região onde se encontrou a maior quantidade de estômatos e que, teoricamente, recebe uma maior quantidade de luz, uma vez que a formação do tanque dificulta a incidência de radiação luminosa na região do embricamento entre as folhas. Os resultados de quantificações endógenas de amido e clorofila total corroboram com essa hipótese, já que as maiores concentrações desses dois compostos foram registradas na porção apical. Se a função fotossintética realmente está vinculada predominantemente à região do ápice, portanto, esperar-se-ia 
que as disponibilidades de energia, poder redutor ou esqueletos carbônicos fossem maiores nessa região das folhas de Vriesea gigantea, onde poderiam, em parte, ser utilizados no metabolismo de assimilação do nitrogênio. Além disso, também foi quantificado os teores endógenos de carboidratos solúveis totais, sendo que as maiores concentrações foram observadas na porção basal foliar. Sugere-se que os carboidratos solúveis foram sintetizados na porção apical, local onde as taxas fotossintéticas seriam mais expressivas, e posteriormente, foram transportados para a porção basal das folhas, onde poderiam exercer um importante papel na regulação da absorção e assimilação do nitrato nessa região foliar. Segundo a literatura, os esqueletos carbônicos podem ser considerados fatores importantes na indução da atividade da NR.

Os aumentos das atividades da NR e urease verificados apenas na porção basal em resposta ao fornecimento de $\mathrm{NO}_{3}{ }^{-} / \mathrm{NH}_{4}{ }^{+}$(3:2) ou uréia também permitiram inferir que grande parte do $\mathrm{NO}_{3}{ }^{-}$ou da uréia absorvidos na base poderiam não estar sendo transportados para a região apical e, portanto, a redução ou a hidrólise completa desses compostos a amônio pareceu ter ocorrido quase que exclusivamente na base da folha. A divisão espacial das funções de hidrólise da uréia e redução de nitrato ocorrendo principalmente na base foliar e a assimilação do amônio em aminoácidos ocorrendo preferencialmente na porção apical, sugere que a bromélia Vriesea gigantea pode estar realizando o transporte de amônio da porção basal para a apical das folhas. Infere-se que esse transporte possa ter ocorrido através da seiva xilemática e do apoplasto. O transporte através dos vasos condutores é uma forma mais rápida da água e os nutrientes alcançarem todos os tecidos ao longo da folha, além de não haver a necessidade do gasto de energia associada com o transporte intracelular e regulação do pH. Além disso, vários estudos já demonstraram que as bromélias formadoras de tanque são mais tolerantes ao cultivo em amônio, uma vez que elas mostraram uma preferência pela forma amoniacal em comparação com a forma nítrica como fonte de nitrogênio inorgânico. Dessa forma, infere-se que a capacidade de transportar o amônio através da seiva xilemática e do apoplasto pode ser uma característica que as bromélias epífitas com tanque adquiriram com a evolução, uma vez que o amônio parece ser a fonte nitrogenada mais disponível em relação ao nitrato no meio epifítico.

A atividade da arginase na porção apical das folhas de bromélias, que receberam uma solução nutritiva contendo uréia, mostraram um aumento da atividade dessa enzima até a $48^{\mathrm{a}}$ hora (maior atividade registrada), após o fornecimento do composto orgânico. Sugeriu-se que, talvez, uma pequena parcela da uréia absorvida possa estar sendo transportada para a região apical foliar, onde poderia estar sendo incorporada diretamente a arginina pela ação da arginase. Entretanto, como os valores absolutos das 
atividades da arginase foram bastante inferiores com aqueles previamente obtidos para as bromélias jovens (2 anos de idade) (CAMBUÍ, resultados não publicados), verificou-se que essa enzima não parece possuir um papel primordial na assimilação da uréia em bromélias adultas cultivadas em casa de vegetação. A urease parece desempenhar um papel mais importante do que a arginase, já que as atividades registradas para as bromélias adultas foram muito superiores à das jovens (40 a 60 vezes maior).

Com relação à preferência por certas fontes nitrogenadas, verificou-se que a bromélia Vriesea gigantea tem preferência por assimilar o nitrogênio proveniente da uréia quando essa se encontra no interior do tanque, mesmo quando também há a disponibilidade de fontes inorgânicas (nitrato ou amônio). As maiores atividades da GS (porção apical) e GDH (porção basal) foram registradas nos dois tratamentos com uréia (1:1 e 1:3) quando comparadas com as dos dois controles (sem nitrogênio e com somente fontes inorgânicas). A uréia absorvida pode estar sendo rapidamente hidrolisada a amônio, sendo esse último assimilado em aminoácidos. A concentração endógena de amônio observada na porção basal torna a hipótese ainda mais plausível, já que as maiores concentrações do composto também foram detectadas nos dois tratamentos com uréia (1:1 e 1:3). Além disso, também foi interessante verificar que apesar das maiores atividades da NR terem sido semelhantes entre o tratamento de proporção 1:1 e o controle com somente fontes inorgânicas (controle 2) na porção basal foliar, a GS não mostrou o mesmo desempenho nos dois tratamentos, sendo que, no controle 2, foi detectado uma atividade cujo valor foi de $50 \%$ daquela registrada no tratamento de proporção 1:1.

As elevadas atividades da GDH registradas na porção basal foliar durante o estudo sobre as preferências de fontes nitrogenadas pela bromélia Vriesea gigantea sugerem que as concentrações de amônio endógeno dos tecidos da base da folha possam ter alcançado altos teores, havendo a necessidade da enzima GDH atuar no sentido aminante de reação, a fim de se assimilar o amônio em glutamato, evitando dessa maneira possíveis danos às células vegetais pelo excesso desse composto inorgânico nos tecidos. Ao analisar as quantificações de amônio endógeno, verificou-se que os tratamentos com uréia (1:1 e 1:3) apresentaram os maiores valores de concentração de amônio nos tecidos da base da folha.

Embora esses resultados suportam a hipótese de que as bromélias epífitas com tanque têm preferência em absorver e assimilar o nitrogênio orgânico (uréia), foi bastante curioso verificar nesse trabalho que as maiores atividades da urease não se expressaram nos tratamentos contendo uréia. É possível que, no momento da coleta, isto é, 9 horas após o fornecimento de uréia, grande parte da uréia absorvida 
possa já ter sido hidrolisada a amônio e, portanto, a urease não estaria tão ativa. Essa hipótese pode ser aventada, uma vez que também não foram observadas altas concentrações de uréia endógena nos tecidos foliares das bromélias pertencentes aos tratamentos com uréia, enquanto que se observaram altas concentrações de amônio endógenos encontrados nas bases foliares desses mesmos tratamentos. Além disso, as altas atividades da urease detectadas na base foliar das bromélias cultivadas sem uréia, sugerem que a urease seja uma enzima constitutiva presente no interior das células vegetais, mesmo sem a presença do seu substrato. Dessa forma, as bromélias se manteriam, normalmente, preparadas para absorver e, rapidamente, hidrolisar a uréia quando essa estivesse disponível no interior do tanque.

Outra hipótese que poderia explicar as baixas atividades da urease detectadas nos tratamentos com uréia seria que esse composto orgânico também estaria sendo assimilado pela ação da enzima arginase, produzindo arginina. Embora na literatura, a arginase seja considerada uma enzima somente capaz de hidrolisar a arginina em uréia e ornitina, alguns estudos em andamento, realizados no Laboratório de Fisiologia Vegetal do IBUSP, indicam a possibilidade da uréia ser incorporada diretamente na formação de aminoácidos. A existência de uma outra via de assimilação desse composto orgânico poderia ser uma importante característica fisiológica que aumentaria a eficiência de captação desse nutriente quando essa fosse disponibilizada do tanque. 


\section{III - BIBLIOGRAFIA}

ADAMS, W.W. \& MARTIN, C.E. Morphological changes accompanying the transition from juvenile (atmospheric) to adult (tank) forms in the Mexican epiphyte Tillandsia deppeana (Bromeliaceae). Am. J. Bot. 73: 1207-1214, 1986a.

ADAMS, W.W. \& MARTIN, C.E. Physiological consequences of changes in life form of the Mexican epiphyte Tillandsia deppeana (Bromeliaceae). Oecologia 70: 298-304, 1986b.

AMARAL, L.I.V.; Gaspar, M.; Costa, P.M.F.; Aidar, M.P.M.; Buckeridge, M.S. Novo método enzimático rápido e sensível de extração e dosagem de amido em materiais vegetais. Hoehnea 34 (4): 425-431, 2007.

BARBOZA, S.B.S.C.; Graciano-Ribeiro, D.; Teixeira, J.B.; Portes, T.A.; Souza, L.A.C. Anatomia foliar de plantas micropropagadas de abacaxi. Pesq. Agropec. Bras.,Brasília 41(2): 185-194, 2006.

BECKER, T.W.; Carrayol, E. and Hirel, B. Glutamine synthetase and glutamate dehydrogenase isoforms in maize leaves: localization, relative proportion and their role in ammonium assimilation or nitrogen transport. Planta 211: 800-806, 2000.

BECKER, T.W.; Carrayol, E.; Hirel, B. Glutamine synthetase and glutamate dehydrogenase isoforms in maize leaves: localization, relative proportion and their role in ammonium assimilation or nitrogen transport. Planta 211: 800-806, 2000.

BENZING, D.H. \& BURT, K.M. Foliar permeability among twenty species of the Bromeliaceae. Bull. Torrey Bot. Club 97: 269-279, 1970.

BENZING, D.H. \& RENFROW, A. The mineral nutrition of Bromeliaceae. Bot. Gaz. 135 (4): 281-288, 1974.

BENZING, D.H. Availability of exogenously supplied nitrogen to seedlings of the Bromeliaceae. Bulletin of the Torrey Botanical Club 97: 154-159, 1970.

BENZING, D.H. Mineral nutrition and related phenomena in Bromeliaceae and Orchidaceae. Quant. Review Biol. 48: 277-290, 1973.

BENZING, D.H. Vascular epiphytes, general biology and related biota. Ashton, P.S. (ed), Cambridge, Cambridge University Press, 1990.

BENZING, D.H.. Bromeliaceae: profile of na adaptative radiation. Cambridge. Cambridge University, 2000.

BENZING, D.H.; Henderson, K.; Kessel, B. and Sulak, J. The adsorptive capacities of bromeliad trichomes.

Am. J. Bot. 63: 1009-1014, 1976. 
BOUTIN, J. Purification, properties and subunit structure of arginase from Iris bulbs. Eur. J. Biochem 127: 237-243, 1982.

BRITTO, D.T. \& KRONZUCKER, H.J. $\mathrm{NH}_{4}{ }^{+}$toxicity in higher plants: a critical review. J.Plant Physiol. 159: 567-584, 2002.

BROWN, R.H. A difference in nitrogen use efficiency in C3 and C4 plants and its implications in adaptation and evolution. Crop Sci. 18: 93-98, 1978.

CAMMAERTS, D. \& JACOBS, M. A study of the role of glutamate dehydrogenase in the nitrogen metabolism os Arabidopsis thaliana. Planta 163: 517-526, 1985.

CARVALHO, H.; Pereira, S.; Sunke, C.; Salema, R. Detection of cytosolic glutamine synthetase in leaves of Nicotiana tabacum L. by immunocytochemical methods. Plant Physiol. 100: 1591-1594, 1992.

CECHIN, I. \& FURNIS, T.F. Effect of nitrogen supply on growth and photosynthesis of sunflower plants grown in the greenhouse. Plant Sci. 166: 1379-1385, 2004.

CHEN, H.; McCaig, B.C.; Melotto, M.; He, S.Y.; Howe, G.A. Regulation of plant arginase by wounding, jasmotate, and the phytotoxin coronatine. JBC 279 (44): 45998-46007, 2004.

CHEN, Y.G \& CHING, T.M. Induction of barley leaf urease. Plant Physiol. 86: 941-945, 1988.

COLLI, S. Etileno. In: KERBAUY, G.B. (ed.). Fisiologia Vegetal. Primeira edição. Guanabara Koogan, Rio de Janeiro, RJ; p. 303-333, 2004.

CORDEIRO, L. Fixação do nitrogênio. In: KERBAUY, G.B. (ed.). Fisiologia Vegetal. Primeira edição. Guanabara Koogan, Rio de Janeiro, RJ; p. 73-93, 2004.

CORUZZI, G.M. Primary N-assimilation into amino acids in Arabidopsis. The Arabidopsis Book, p 1-17, 2003.

CRUZ, C.; Bio, A.F.M.; Dominguez-Valdivia, M.D. How does gutamine synthetase activity determine plant tolerance to ammonium? Planta 223: 1068-1080, 2006.

de RUITER, H. \& KOLLÖFFEL, C. Arginine cababolism in the cotyledons of developing and germinating pea seeds. Plant Physiol. 73: 525-528, 1983.

DUBOIS, M.; Gilles, K.A.; Hamilton, J.K.; Rebers, P.A.; Smith, F. Colorimetric method for determination of sugars and related substances. Anal. Chem. 28: 350-356, 1956.

ENDRES, L. \& MERCIER, H. Amino acid uptake and profile in bromeliads with different habits cultivated in vitro. Plant Physiol. Biochem. 41: 181-187, 2003.

ENDRES, L. \& MERCIER, H. Ammonium and urea as nitrogen sources for bromeliads. J. Plant Physiol. 158: 205-212, 2001b.

ENDRES, L. \& MERCIER, H. Influence of nitrogen forms on the growth and nitrogen metabolism of bromeliads. J. Plant Nutr. 24 (1): 29-42, 2001a.

FARNDEN, K.J.S. \& ROBERTSON, J.G. Methods for studying enzyme involved in metabolism related to nitrogenase. In: BERGSEN, F.J. (ed.). Methods for Evaluating Biological Nitrogen Fixation. Jonh Wiley \& Sons Ltd.; p. 279-286, 1980. 
FERNANDES, M.S. \& SOUZA, S.R. Transporte no Floema. In: KERBAUY, G.B. (ed.). Fisiologia Vegetal. Primeira edição. Guanabara Koogan, Rio de Janeiro, RJ; p. 94-113, 2004.

FINNEMANN, J. \& SCHJOERRING, J.K. Translocation of NH4+ in oilseed rape plants in relation to glutamine synthetase isogen expression and activity. Physiol. Plant. 105: 469-477, 1999.

FLUENTES, S.I.; Allen, D.J.; Ortiz-Lopez, A. and Hernández, G. Over-expression of cytosolic glutamine synthetase increases photosynthesis and growth at low nitrogen concentrations. J. Exp. Bot. 52 (358): 1071-1081, 2001.

FORD, B.G. \& COLE, J.A. Nitrate finds a place in the sun. Plant Physiol. 131: 395-400, 2003.

FURLANI, A.M.C. Nutrição mineral. In: KERBAUY, G.B. (ed.). Fisiologia Vegetal. Primeira edição. Guanabara Koogan, Rio de Janeiro, RJ; p. 40-76, 2004.

GERENDÁS, J. \& SATTELMACHER, B. Influence of Ni supply on growth and nitrogen metabolism of Brassica napus L. grown with $\mathrm{NH}_{4} \mathrm{NO}_{3}$ or urea as N source. Ann. Bot. 83: 65-71, 1999.

GERENDÁS, J. \& SATTELMACHER, B. Significance of Ni supply for growth, urease activity and the concentrations of urea, amino acids and mineral nutrients of urea grow plants. Plant Soil 190: 153162, 1997.

GOODWIN, T.W. \& MERCER, E.I. Introduction to Plant Biochemistry, $2^{\text {nd }}$ edn, Pergamon Press, Oxford, 1983.

GUO, S-W., Zhou, Y.; Gao, Y-X.; Li, Y.; Shen, Q-R. New insights into the nitrogen form effect on photosynthesis and photorespiration. Pedosphere 17 (5): 601-610, 2007.

HAK, R.; Rinderle-Zimmer, U.; Lichtenthaler, H.K.; Natr, L. Chlorophyll a fluorescence signatures of nitrogen deficient barley leaves. Photosynthetica 28:151-159, 1993.

HELDT, H-W. Nitrate assimilation. In HELDT, H-W., Plant Biochemistry \& Molecular Biology, Oxford University Press, p. 247-276, 1997.

HOGAN, M.E.; Swift, I.E.; Done, J. Urease assay and ammonia release from leaf tissues. Phytochemistry 22: 663-667, 1983.

HUSTED, S.; Hebbern, C.; Mattsson, M.; Schojoerring, J.K. A critical experimental evaluation of methods for determination of NH4+ in plant tissue, xylem sap and apoplastic fluid. Physiol. Plant. 109: 167179, 2000.

INSELSBACHER, E.; Cambuí, C.A.; Richter, A.; Stange, C.F.; Mercier, H.; Wanek, W. Microbial activities and foliar uptake of nitrogen in the epiphytic bromeliad Vriesea gigantea. New Phytol. 175: 311-320, 2007.

JAWORSKI, E. Nitrate reductase assay in intact plant tissues. Biochem. Biophys. Res. Comm. 43 (6): 1274-1279, 1974.

KANG, J.H. \& CHO, Y.D. Purification and properties of arginase from soybean, Glycine max, Axes. Plant Physiol. 93: 1230-1234, 1990. 
KING, J.E. \& GIFFORD, D.J. Amino acid utilization in seeds of loblolly pine during germination and early seedling growth .1. Arginine and arginase activity. Plant Physiol. 113 (4): 1125-1135, 1997.

KNUDSON, L. A new nutrient soluyion for germination for orchid seed. Amer. Orch. Soc. Bull. 15: $214-$ 217, 1946.

KOLLÖFFEL, C. \& VAN DIJKE, H.D. Mitochondrial arginase activity from cotyledons of developing and germinating seeds of Vicia faba L. Plant Physiol. 55: 507-510, 1975.

KRAUSS, B.H.. Anatomy of the vegetative organs of the pineaple. Ananas comosus (L.) Merr. II. The leaf. Bot. Gaz. 110: 333-404, 1949.

LAWLOR, D.W. Carbon and nitrogen assimilation in relation to yield: mechanisms are the key to understanding production systems. J. Exp. Bot. 53 (370): 773-787, 2002.

LEA, P.J. Nitrogen metabolism. In: LEA, P.J. \& LEEGOOD, R.C. (eds.). Plant Biochemistry and Molecular Biology. $1^{\text {a }}$ ed. England: John Wiley \& Sons Ltda.; pp: 155-180, 1993.

LEHNINGER, A.L.; Nelson, D.L.; Cox, M.M. Biossíntese de aminoácidos, nucleotídeos e moléculas relacionadas. In: LEHNINGER, A.L.; Nelson, D.L.; Cox, M.M. (eds.). Princípios de Bioquímica. $2^{\mathrm{a}}$ ed. São Paulo: Savier Editora de Livros Médicos Ltda. p. 514-551, 2000.

LEME E.M.C. \& MARIGO, L. C. Bromélias na natureza. Marigo Comunicação Visual Ltda. Rio de Janeiro, 1993.

LICHTENTHALER HK. Chlorophylls and Carotenoids: pigments of photosynthetic biomembranes. Methods Enzymol. 148: 350-382, 1987.

LILLO, C. Light regulation of nitrate reductase in green leaves of higher plants. Physiol. Plant. 90: 616-620, 1994.

LOQUÉ, D. \& von WIRÉN, N. Regulatory levels for the transport of ammonium in plant roots. J. Exp. Bot. 55: 1293-1305, 2004.

MACKINGTOSH, C. Regulation of cytosolic enzymes in primary metabolism by reversible protein phosphorylation. Curr. Opin. Plant Sci. 1: 224-229, 1998.

MAE, T. Physiological nitrogen efficiency in rice: Nitrogen utilization, photosynthesis and yield potential. Plant Soil 196: 201-210, 1997.

MAJEROWICZ, N. Fotossíntese. In: KERBAUY, G.B. (ed.). Fisiologia Vegetal. Primeira edição. Guanabara Koogan, Rio de Janeiro, RJ; pp: 114-178, 2004.

MARSCHNER, H. Mineral nutrition of higher plants. Second edition. Academic Press London, 1995.

MASCLAUX, C.; Quilleré, I.; Gallais, A. and Hirel, B. The challenge of remobilization in plant nitrogen economy. A survey of physio-agronomic and molecular approaches. Ann. Appl. Biol. 138: 69-81, 2001.

MASCLAUX, C.; Valadier, M.; Brugière, N.; Morot-Gaudry, J. and Hirel, B. Characterization of the sink/source transition in tobacco (Nicotiana tabacum L.) shoots in relation to nitrogen management and leaf senescence. Planta 211: 510-518, 2000. 
MASCLAUX-DAUBRESSE, C.; Valadier, M.H.; Carrayol, E.; Reisdorf-Cren, M. and Hirel, B. Diurnal changes in the expression of glutamate dehydrogenase and nitrate reductase are involved in the $\mathrm{C} / \mathrm{N}$ balance of tabacco source leaves. Plant Cell Environ. 25: 1451-1462, 2002.

MATSUMOTO, H.; Hasegawa, Y.; Kobayashi, M.; Takahashi, E. Inducible formation of urease in Canavalia ensiformis. Physiol. Plant. 21: 872-881, 1968.

MATSUMOTO, H.; Yasuda, T.; Koayashi, M.; Takahashi, E. The inducible formation of urease in rice plants. Soil Sci. Plant Nutr. 12: 239-244, 1966.

MATT, P.; Schurr, U.; Krapp, A.; Stitt, M. Growth of tobacco in short day conditions leads to high starch, low sugars, altered diurnal changes of the nia transcript and low nitrate reductase activity and an inhibition of amino acid synthesis. Planta 207: 27-41, 1998.

MAUSETH, J.D. (ed.). Botany na Introduction of Plant Biology. Terceira edição. Impresso nos Estados Unidos da América, 2003.

MAXIMOV, N.A. The physiological significance of the xeromorphic structure of plants. In: Symposium on Xeromorphy, International Botanical Congress, Cambridge; p. 273-282, 1930.

MCCULLOUGH, H. The determination of ammonia in whole blood by a direct colorimetric method. Clin Chim Acta. 17(2): 297-304, 1967.

MERCIER, H.; Kerbauy, G.B.; Carvalho, M.T.V.; Derbyshire, E. Growth and GDH and AAT isoenzyme patterns in terrestrial and epiphytic bromeliads as influenced by nitrogen source. Selbyana 18 (1): 8994, 1997.

MICALLEF, B.J. \& SHELP, B.J. Arginine metabolism in developing soybean cotyledons. Plant. Physiol. 90: 624-630, 1989.

MIFFLIN, B.J. \& LEA, P.J. Ammonia assimilation. In: MIFFLIN, B.J., EE Con, eds, The Biochemistry of Plants. Vol 5: amino acids and derivatives. Academic Press, New York; p. 169-202, 1980.

MIFLIN, B.J. \& HABASH, D.Z. The role of glutamine synthetase and glutamate dehydrogenase in nitrogen assimilation and possibilities for improvement in the nitrogen utilization of crops. J. Exp. Bot. 53 (370): 979-987, 2002.

MURASHIGE, T. and SKOOG, F. A revised medium for rapid growth and bioassays with tabacco tissue culture. Physiol. Plant. 15: 473-479, 1962.

NICOULAUD, B.A.L. \& BLOOM, A.J. Absorption and assimilation of foliarly applied urea in tomato. $\mathbf{J}$ Am. Soc. Hortic. Sci. 121: 1117-1121, 1996.

NIELSEN, K. \& SCHJOERRING, J.K. Regulation of apoplastic NH4+ concentration in leaves of oilseed rape. Plant Physiol. 118: 1361-1368, 1998.

NIEVOLA, C.C.; Mercier, H.; Majerowicz, N. Levels of nitrogen assimililatin in bromeliads with different growth habits. J. Plant Nutr. 24(9): 1387-1398, 2001a.

NIEVOLA. C.C. Influência da nutrição nitrogenada sobre a atividade de enzimas do metabolismo do nitrogênio em bromélias cultivadas in vitro. Dissertação (Mestrado em Botânica) - Instituto de Biociências, Universidade de São Paulo, São Paulo, 1997. 
NIEVOLA. C.C.; Mercier, H.; Majerowicz, N. Uréia: uma possível fonte de nitrogênio orgânico para as bromélias com tanque. Bromélia 3: 44-48, 2001b.

NORDIN, A. \& NAESHOLM, T. Nitrogen storage in nine boreal understorey plant species. Oecologia 110: 487-492, 1997.

OAK, A. Evidence for deamination by glutamate dehydrogenase in higher plants: reply. Can. J. Bot 73 : 1116-1117, 1995.

OLIVARES, E. \& MEDINA, E. Carbon dioxide exchange, soluble carbohydrates and acid accumulation in a fructan accumulating plant: Fourcroya humboldtiana Treal.. J. Exp. Bot. 41(226): 579-585, 1990.

OSUJI, G.O.; Reyes, J.C.; Mangaroo, A.S. Glutamate dehydrogenase isomerization: A simple method for dagnosing nitrogen, phosphorus and potassium sufficiency in maize (Zea mays L.). J. Agric. Food Chem. 46: 2395-2401, 1998.

PACZEK, V.; Dubois, F.; Sangwan, R.; Morot-Gaudry, J-F.; Roubelakis-Angelakis, K.A.; Hirel, B. Celular and subcellular localisation of glutamine synthetase and glutamate dehydrogenase in grapes gives new insights on the regulation of carbon and nitrogen metabolism. Planta 216: 245-254, 2002.

PADILHA, V. Bromeliads. New York, Crow Publishers Inc., 1973.

PAGEAU, K.; Reisdorf-Cren, M.; Morot-Gaudry, J-F.; Masclaux-Daubresse, C. The two senescence-related markers, GS1 (cytosolic glutamine synthetase) and GDH (glutamate dehydrogenase), involved in nitrogen mobilization, are differentially regulated during pathogen attack and by stress hormones and reactive oxygen species in Nicotiana tabacum L. leaves. J. Exp. Bot. 53 (3): 547-557, 2006.

PÉREZ-SOBA, M.; Stulen, I. \& van der Eerden, L.J.M.. Effect of atmospheric ammonia on the nitrogen metabolism of Scots pine (Pinus sylvestris) needles. Physiol. Plant. 90: 629-636, 1994.

PIMENTA, J.A. Relações Hídricas. In: KERBAUY, G.B. (ed.). Fisiologia Vegetal. Primeira edição. Guanabara Koogan, Rio de Janeiro, RJ; p. 1-39, 2004.

POLACCO, J. C.; Holland, M. A. Roles of urease in plant cells. International Review of Cytology 145: 65103, 1993.

POPP, M.; Janett, H-P.; Lüttge, U.; Medina, E. Metabolite gradients and carbohydrate translocation in rosette leaves of CAM and C3 bromeliads. New Phytol. 157: 649-656, 2003.

POREMBSKA, Z. Different species of arginase in animal-tissues. Enzyme 15 (1-6): 198-209, 1973.

PROENÇA, S.L. \& SAJO, M.G. Estrutura foliar de espécies de Aechmea Ruiz \& Pav. (Bromeliaceae) do Estado de São Paulo, Brasil. Acta Bot. Bras. 18 (2): 319-331, 2004.

RAI, A.N.; Rowell, P. \& Stewart, W.D.P. Interations between cyanobacterium and fungus during ${ }^{15} \mathrm{~N}_{2}{ }^{-}$ incorporation and metabolism in the lichen Peltigera canina. Archives of microbiology 134: 136-142, 1983.

ReInbothe, H. \& MOTHES, K. Urea, ureides and guanidines in plant. Ann. Rev.Plant Physiol. 13: 129150, 1962.

SAKAI, W.S. \& SANDFORD, W.G. Ultrastructure of the water-absorbing trichomes of pineapple (Ananas comosus, Bromeliaceae). Ann. Bot. 46: 7-11, 1980.

SATTELMACHER, B. The apoplasto and its significance for plant mineral nutrition. New Physiol. 149: 
167-192, 2001.

SCHJOERRING, J.K.; Husted, S.; Mäck, G.; Mattsson, M. The regulation of ammonium translocation in plants. J. Exp. Bot. 53(370): 883-890, 2002.

SODEK, L. Metabolismo do Nitrogênio. In: KERBAUY, G.B. (ed.). Fisiologia Vegetal. Primeira edição. Guanabara Koogan, Rio de Janeiro, RJ; p. 94-113, 2004.

SPLITTSTOESSER, W.E. The appearance of arginine in pumpkin cotyledons. Characterization of arginase. Phytochemistry 8: 753-758, 1969.

STITT, M. Nitrate regulation of metabolism and growth. Curr. Opin Plant Biol. 2: 178-186, 1999.

STITT, M.; Müller, C.; Matt, P.; Gibon, Y.; Carillo, P.; Morcuende, R.; Scheible, W-R.; Krapp, A. Steps towards an integrated view of nitrogen metabolism. J. Exp. Bot. 53 (370): 959-970, 2002.

STÖHR, C. \& MÄCK, G. Diurnal changes in nitrogen assimilation of tobacco roots. J. Exp. Bot. 52 (359): 1283-1289, 2001.

TAIZ, L. \& ZEIGER, E. Assimilation of Mineral Nutrients. In: TAIZ, L. \& ZEIGER, E. (eds.). Plant Physiol.. Third edition. Sunderland, Massachusetts: Sinauer Associates, Inc., Publishers.; p. 259-266, 2000.

TAKAHASHI, C.A.; Ceccantini, G.C.T.; Mercier, H.. Differential capacity of nitrogen assimilation between apical and basal leaf portions of a tank epiphytic bromeliad. Braz. J. Plant Physiol. 19 (2): 119-126, 2007.

TAMAKI, V. \& MERCIER, H.. Effects of different ammoniacal nitrogen sources on N-metabolism of the atmospheric bromeliad Tillandsia pohliana Mez. Revta. Brasil. Bot. 24 (4): 407-413, 2001.

TAYLOR, A.A. \& STEWART, G.R. Tissue and subcellular localization of enzymes of arginine metabolism in Pisum sativum. Biochemical and Biophysical Research Communication 101(4): 1281-1298, 1981.

TEIXEIRA, J.; Pereira, S.; Cánovas, F.; Salema, R. Glutamine synthetase of potato (Solanum tuberosum L. cv. Désirée) plants: cell- and organ-specific expression anda differential developmental regulation reveal specific roles in nitrogen assimilation and mobilization. J. Exp. Bot. 56 (412): 663-671, 2005.

TERCE-LAFORGUE, T.; Mäck, G. and Hirel, B. New insights towards the function of glutamate dehydrogenase revealed during source-sink transition of tobacco (Nicotiana tabacum) plants grown under different nitrogen regimes. Physiol. Plant. 120: 220-228, 2004.

TOBIN, A.K. \& YAMAYA, T. Celular compartmentation of ammonium assimilation in rice and barley. $\mathbf{J}$. Exp. Bot. 52: 591-604, 2001.

TURANO, F.J.; Thakkar, S.S.; Fang, T. and Weisemann, J.M. Characterization and expression of NAD (H) dependent glutamate dehydrogenase genes in Arabidopsis. Plant Physiol. 113: 1329-134, 1997.

VANETEEN, C.H.; Miller, R.W.; Wolff, I.A.; Jones, Q. Aminoacid composition of seeds from 200 angiospermous plant species. Agric. Food Chem. 5: 399-410, 1963. 
VERHOEVEN, A.S.; Demmig-Adams, W.W.; Adams III. Enhanced empployment of the xanthophyll cycle and thermal energy dissipation in spinach exposed to high light and N stress. Plant Physiol. 133: 817824, 1997.

WEATHERBURN, M.W. Phenol-Hypochlorite Reaction for Determination of ammonia. Analytical Chemistry 39: 971-974, 1967.

WITTE, C-P. \& Medina-Escobar, N. In-gel detection of urease with nitroblue tetrazolium and quantification of the enzyme from different crop plants using the indophenol reaction. Anal. Biochem. 290: 102-107, 2001.

WITTWER, S.H.; Bokovac, M.J.; Tukey, H.B. Advances in foliar feeding of plant nutrients. In MCVICKAR, M.H., (ed), Fertilizer Technology and Usage. Soil Science Society of America, Madison, WI, p. 429-455, 1963.

ZONIA, L. E.; Stebbins, N. E.; Polacco, J. C. Essential role of urease in germination of nitrogen limited Arabidopsis thaliana seeds. Plant Physiol. 107: 1097- 1103, 1995.

ZOTZ, G.; Reichling, P.; Valladares, F. A simulation study on the importance of size-related changes in leaf morphology and physiology for carbon gain in na epiphytic bromeliad. Ann. Bot. 90: 437-443, 2002. 